\title{
Learning to Teach in the Field: Five Professors Tell How Running an Overseas Study Tour Improved Their Classroom Teaching
}

\author{
Katherine Ellinghaus \\ La Trobe University
}

Jennifer Spinks

University of Melbourne

Glenn Moore

Japan Broadcasting Corporation

Paul Hetherington

University of Canberra

Cassandra Atherton

Deakin University

\begin{abstract}
:
This article examines the positive impact of overseas study tours on the teaching philosophies and classroom strategies used by the professors running the tours. While education scholars have identified long-term benefits of overseas study tours for students, less attention has been paid to flow-on benefits for teachers. This article aims to address this gap in the literature by having five Australian professors describe how their international study tour experiences changed and improved their teaching in the classroom. The article shows that in the process of developing a successful overseas study tour, professors can learn lessons about teaching that they can use productively in the classroom.
\end{abstract}

\section{Introduction}

The genesis of this article was a survey of overseas study tour students from the University of Melbourne. Students who had taken the study tour over an eleven-year period, from 2000 to 2011, were surveyed in 2014. The results, which were published in the Australasian Journal of American Studies, indicated that the students placed great value on the study tour as a learning experience (Atherton \& Moore, 2016). This was no real surprise. Storied historians such as Alice Kessler Harris, David Hackett Fisher, and James McPherson all believe that having a sense of place leads to a better understanding of history. McPherson, for instance, makes his Civil War students walk around the Gettysburg battlefield. "One can read millions of words about the battle," he explained, "but only by going there can one really begin to understand it" (McPherson, 2000, p. 264). Melbourne history students seemed to agree. There was fierce competition for places on study tours, and evaluations 
that students completed for the university administration at the end of each tour were overwhelmingly positive. However, the surprising thing was the regularity with which students indicated that they had accrued long-term benefits from the tour. This was in keeping with emerging scholarship that shows, as Daniel Reynaud and Maria Northcote argue, that the impact of "participation in study tours can be deep and life long" (2011, p. 255). Nevertheless, the certainty with which the surveyed students attributed positive academic, professional, social, and civic benefits to their study tour experience exceeded our expectations, and was a strong indicator of the worth of these study tours. ${ }^{1}$

In spite of positive assessments and the popularity of overseas study tours with students-the Melbourne newspaper The Age reported that students "flock" to tours when they are offered-the concept has struggled to gain acceptance in Australian universities (Kutchel, 2015). Even in the United States, where there is a far longer history of experiential learning than in Australia, and where internships and service learning are accepted parts of college curriculums, "field-based pedagogies struggled to gain legitimacy" in the liberal arts (Eyler, 2009, p. 25). Ironically, the popularity of study tours among students is viewed with suspicion by some academics, who dismiss them as "academic fluff," indicative of "anti-intellectual trends" in higher education (Kiely, 2005, p. 4; Kolb, 1984, p. 3). While our survey indicated this was not the case, there are pragmatic reasons why academics hesitate to run study tours. Organizing a tour is hard work and running one is stressful. Juggling these demands with other teaching duties and the ever-present pressure to publish is daunting. According to Wurdinger and Allison, time pressure is the number one reason academics do not use study tours (2017, p. 23).

Every professor who contributed to this article had their own reasons for disregarding these negative factors and running a study tour. The long hours spent devising a coherent international program and the intense three weeks spent overseas, in the hope that the activities ran smoothly and that no student was lost or fell ill, were even more demanding than the naysayers predicted. And yet we kept running the tours. This was partly due to positive reactions from the students-believing that experiential learning worked made a difference. However, we also realized that the study tours bestowed long-term benefits on us as teachers. The source of these benefits was the need to understand what makes a study tour work. As John Dewey, the founding father of experiential learning, warned, "the belief that all genuine education comes about through experience does not mean that all experiences are equally educative" (1938, p. 25). A successful study tour requires knowing what activities work in the field and how to help students get the most out of them. The necessity to acquire this understanding forced us to become better teachers, and each of us applied our newfound knowledge when we were back in our traditional classroom settings.

In this article, five professors at Australian universities describe how their international study tour experiences changed and improved their teaching in the classroom. Their responses differed, which is not surprising given that they teach in different disciplines, at different universities, to students with different backgrounds and aspirations. However, patterns emerged. Two broad lessons learned from the study tours translated into successful classroom outcomes. The first was that

\footnotetext{
${ }^{1}$ Our survey echoed the findings of Coker and Porter that over $60 \%$ of students who undertook experiential learning at Elon University reported "career development benefits." J. Coker \& D. Porter. (2015, January/February). Maximizing experiential learning for student success. Change: The Magazine of Higher Learning, 67.
} 
students respond positively to engaging directly with material culture — art, artifacts, documents, and letters. The second was to the application of teaching strategies that worked in the field to the classroom. Moreover, the boundary between the two approaches was sometimes blurred. For instance, one professor who was inspired to use more material culture in the classroom soon found herself replacing exams and essays with non-traditional assessment tasks such as curating an exhibition.

In spite of these patterns and overlaps, this article does not seek to set out a single blueprint for teaching based on study tour experiences. It simply makes the point that in the process of honing a workable study tour, professors learn lessons about teaching that they can use productively in the classroom.

\section{Glenn Moore: Giving Students a Challenge}

My study tour involved taking a group of 60 University of Melbourne students to the United States for three weeks, spending a week each in Boston, New York, and Washington, DC. The students stayed in college dorms (Emerson College in Boston, the Fashion Institute of Technology in New York, and American University in Washington, DC). They had a free day in each city, while the other six days consisted of organized activities aimed at bringing the American Studies lessons they learned in their classrooms to life. To that end, they met with politicians, academics, union officials, and community organizers, visited museums, national parks, and historic sites, and participated in activities such as working in a food bank and attending a gospel church service.

Coordinating this study tour for eleven years (sometimes with a colleague) influenced my teaching in many ways. Seeing what did and did not capture the imagination of students in the field influenced the content of my courses, and I even implemented some of the activities and ideas provided by museums we visited. The Director of Education at the Lower East Side Tenement Museum, for instance, suggested classroom activities that gave my students a better sense of the dark, cramped tenement apartments than they would have gained through reading alone (Bader, 2013, pp. 94-99). One particularly effective strategy was a role-playing exercise in which the students took on the identities of family members and negotiated among themselves the best use of the limited space in their imaginary apartment. I found that this exercise required students to familiarize themselves with the material objects that constituted daily life in New York in the Gilded Age, such as winter coats that needed to be stored in wardrobes, a heavy iron used by the mother to press clothes, and a thick family bible. Grappling with how to fit these objects in a small apartment gave the students insight into what it was like to live on the Lower East Side a century ago.

The students' willingness to use material culture to build a picture of life in the past in the same way that detectives use material evidence to solve crimes reflected the enthusiasm and hard work I had seen on the study tour, and restored my confidence in students' willingness to learn, and to tackle difficult material. Peter Carlson and Mark Fleisher have outlined a general decline in academics' faith in students, with the chief culprit being the business model increasingly adopted by universities, in which students are seen as "customers." The problem being that academics come to believe that student customers "shop for the courses with the least work and highest grades" (2002, p. 1106). The financial commitment asked of study tour students-airfares, accommodation, etc.made the customer analogy seem particularly ominous, but somehow, our students did not behave in 
the way Carlson and Fleisher predicted. Indeed, they seemed to relish the challenge of a demanding schedule packed with meetings during which they were required to engage with public figures and scholars (Atherton \& Moore, 2016, p. 90).

This willingness to rise to a challenge was evident when the students undertook a walking tour of the monuments in the Washington Mall. Although the tour looked comfortably achievable when it was planned, it took almost four hours to complete. When the group finally made it to the metro station, they were exhausted. I concluded that the walking tour was too arduous; however, the next morning, the students discussed it in positive terms. Indeed, many chose to write essays based on the memorials they observed. Students also reacted positively to a range of other difficult situations-working in a food bank in the Bronx, and having to answer tough questions put to them by a Harvard professor-, supporting Nicholas Gair's argument that the point of the study tour is to place students in "challenging situations" (1997, p. 1).

When I was back at Melbourne University it made sense to continue challenging students in the classroom. I set difficult texts. I put students on the spot in discussion classes, and created challenging assessment tasks. I was strict about deadlines whereas I had previously been flexible. Just as all students were required to walk around the Washington Mall with the group, every student had to finish the final essay by the due date. But most importantly, I anchored my courses with a theme that tied everything together and, because it was complex, also challenged the students. This approach flowed directly out of the study tour. As Mel Silberman has explained, for experiential learning to work, students need to "see the common thread in the program" (2010, p. 5). However, because we were trying to give our students the broadest range of experiences possible, we ran the risk of confronting them with an impossibly eclectic itinerary/curriculum. Our solution was to link activities to a central theme: The American Dream. From the students' point of view, the only catch was that the American Dream is a notoriously slippery concept. We had them read key texts, including Facing Up to the American Dream and The American Dream: A Short History (Hochschild, 1995; Cullen, 2003). Then, in the spirit of a study tour, we scheduled in-situ meetings with the authors of those two books. The meetings stretched the students to the limit. They had to grapple with Jim Cullen's contention that the "Dream" evolved over time. The Puritans, he said, had a dream. It was different than ours, but, he argued, "you'll never really understand what it means to be an American . . . if you don't try to imagine the shape of that dream" (2003, p. 13). In a meeting held in a Harvard classroom, Jennifer Hochschild then confronted students with the paradox of poor people in today's America who often believe in the American Dream more fervently than people who have achieved the success and material trappings we commonly associate with the concept.

The students engaged intelligently with those two authors, but the scholarly literature on experiential learning stresses the need to continue reinforcing the linking theme throughout the study tour. As Wurdinger and Allison cautioned, "going on a field trip to a park, for example, might not result in a learning experience if it is not guided by the educator and then reflected on by the students" (2017, p. 16). Bearing in mind that our students were trying to link activities as diverse as a witch trial re-enactment in Salem and a meeting with Teamsters boss Jim Hoffa in Washington to the complexity of the American Dream, we took Mel Silberman's advice and held briefing sessions each morning before we set out (2010, p. 5). We also had discussions at the end of the day, during which the students reflected on what they had done. In these sessions, they discussed how the day's 
activity related to the linking American Dream theme, and how their understanding of the concept was evolving. As Roger Greenway has written, "experience can come alive in the de-brief" (2007, p. $60)$.

After returning to Melbourne and reflecting on my teaching, I realized that while my courses had a narrative structure, they lacked the tight, challenging theme that had so successfully anchored the study tour. My first experiment with a study tour-inspired argument was in a course on the United States from the Gilded Age to World War Two. My argument was that the critical factor behind the United States becoming "modern" was not technology, but rather the government's ability to control and regulate society to make it better. To that end, we studied the shift from the freewheeling laissez-faire capitalism of the late 19th century to the government interventionism that marked the Progressive era and the New Deal. The point here was not to limit students to a prescribed interpretation, but rather to challenge them with a clear, unambiguous argument, to which they were free to respond in any way that they felt inclined. Drawing on my study tour experience, I ensured that the theme and course objectives were repeated and built upon as the semester unfolded. In place of the study tour's evening "de-briefs," we continually framed tutorial discussions around the modernity theme. Education scholarship suggested that this attempt to impose clarity was pedagogically sound. Indeed, according to Hativa, Barak, and Simhi, students see "unambiguous goals . . and clarity" as "the most important teaching characteristics" (2001, pp. 701, 702). Similarly, Ohio State University Education Professor Donald Cruikshank reported, "teachers who rated most highly on clarity . . produced higher student achievement and satisfaction" (1985, p. 45). The results bore out these predictions. The course achieved strong approval ratings in the survey conducted by the university at the end of semester, and perhaps even more significantly, it was reviewed positively in the student-run magazine Farrago. The student reviewer believed that the weekly topics were "chapters, and put together they spelt out an overarching theme." Moreover, the definition of modernity that I proposed was "welcomingly provocative and made for good tutorial conversation" (2006, p. 48). The lesson was clear. If students are given a challenge, and if they understand what that challenge involves in clear, unambiguous terms, they will respond positively.

\section{Katherine Ellinghaus: Finding a Teaching Persona}

I was involved for eight years in the University of Melbourne "American Dream" study tour described by my colleague above. I began as the tutor, co-coordinated the tour for three or four years, and then, when my job description changed from teaching-focused to research-focused, remained involved on an informal basis. One reason for this was that I was seduced by the annual chance to experience student enthusiasm that is becoming, sadly, increasingly rare in the modern Australian university (Boucher \& Arrow, 2016, pp. 592-607). Thus, even after I was no longer officially teaching the subject, I made sure that my research trips included a segment where I met up with my colleague and his students and participated in some of the visits.

I have written before that one of my favorite aspects of running an international study tour was the process of "getting there"-i.e., the lessons that students learned not at the visits themselves, but on the way to or from them (Ellinghaus, 2013, pp. 160-166). The casual conversations that I had on the bus or the subway, walking or sitting side by side with students rather than facing them at the front of the classroom, have easily been some of the best teaching moments of my career. I have vivid memories of the thrill of speaking, finally, to one of the "quiet ones" as we walked down the 
hill from Salem Village. On that walk, I had the opportunity to draw this student out and hear her insights. I was later able to call on her in class in a way that comfortably included her in the discussion for perhaps the first time since we had arrived. And even though, as Mary M. Reda reminds us, students who do not speak all the time should not be seen as inherently problematic, it is easy enough to see why casual conversations are advantageous for shy individuals who might appreciate the opportunity to try out their ideas or questions on their lecturer in a one-on-one manner (2009).

Of course, there is much more to unpack in such interactions, which speaks to why overseas study tours are of great benefit to staff, as well as to students. These teaching moments were a source of satisfaction not just to the student but also to me. They could take place because, on the overseas study tour, I, as the teacher, was accessible in ways that office hours and friendly chats after tutorials and lectures could never provide. I was present and unavoidably available on bus and train trips and on journeys by foot. More than that, as I engaged in visits and met scholars, activists, politicians, and community leaders, it was possible for students to see their teacher learning alongside them. In the lead-up to my first trip experience as tutor, I remember feeling quite anxious. I knew that, unlike my colleague, who had been teaching the subject for some time, I was just as unfamiliar with the places and people that we would be seeing as the students. How, I wondered, would I be able to pull off the persona of expert, day after day, as I encountered new things for the first time?

Once my first study abroad teaching experience began, I quickly realized that trying to pretend to be an expert was impossible and was unlikely to result in a positive learning environment. It was a much better idea, I discovered, to be open about the fact that I was learning alongside the students. I wondered and wandered alongside them, asked questions of them that I did not know the answers to, and solicited their opinions about aspects of the course that I found genuinely puzzling. My discussions with students became less about telling them facts and informing them of the "right" perspective and more about exploring the significance of a shared experience.

Jay Parini has written about the fact that all teaching involves, to some extent, the development of a "persona." "Nobody just walks into a classroom and begins to teach," he argues, "without some consideration of self-presentation, much as nobody sits down to write a poem, an article or a novel without considering the voice behind the words" (2005, p. 61). Parini argues that teaching is "a conscious act of self-creation, as self-performance" and encourages us to recognize that it is an act of courage to step into a classroom wearing "a mask that you know is a construction, hiding behind it, letting it give shape and substance to your formulations, letting the mask become your face" (2005, p. 70). He traces in detail how in the process of learning to be a teacher, a junior academic must "try on countless masks before finding one that fits" (2005, pp. 67, 62). A study tour, with its daily interactions with students, provides a hothouse environment for this kind of development. Teachers are forced to find a persona that they can maintain comfortably for long periods as they function as tour guide and fellow tourist as well as facilitator and lecturer.

In 1994, Anthony F. Grasha observed five different faculty teaching styles, all of which are normally combined by individuals in their teaching practices. At one end of the scale is the "expert" who "strives to maintain status as an expert among students by displaying detailed knowledge." 
Other teachers teach using "formal authority," emphasizing their status among students. The "personal model" is used by teachers who believe in "teaching by personal example" and who model a prototype for how to think and behave. The "facilitator" emphasizes the personal nature of teacher-student interactions and "guides students by asking questions, exploring options, suggesting alternatives, and encouraging them to develop criteria to make informed choices." Finally, the "delegator" is concerned with encouraging students' capacity to function autonomously (1994, pp. 142-149).

In discarding the "expert" model in favor of the "personal model" of the "facilitator," I was, as a female academic, following the path of least resistance. There has been a plethora of recent research that uses student evaluations to explore the differences in how students perceive their teachers according to gender. Women find more personal comments on their teaching evaluations than men and are perceived by students as less smart than their male colleagues (MacNeill, Driscoll, \& Hunt, 2015; Pritchard, 2015.) Thus, for women, some teaching styles are better received than others. Grasha found that women received somewhat lower scores than men when they used expert and formal authority models of the Teaching Styles Inventory and somewhat higher scores when using the facilitator and delegator styles (1994, p. 148).

Working with rather than against these gender inequities, I have tried to bring that lessoneducating by showing my own learning-into all my subsequent teaching. I have consciously tried to imbue all my interactions with students with the sense that I am open to conversation and new ideas. I tell students about my research problems, my mistakes, and the moments when I gained a particular understanding. I try not to teach as though I have all the answers. I try to run tutorials and seminars as if they are a conversation that I value, and which I view as contributing to my own learning. Part of this strategy is — to a certain extent—about being personally upfront, i.e., showing the hard work and wrong turns behind conclusions. Conversations happen more easily if you ask students to think directly about how they learn and about how you are going to teach. I try to teach with the persona of someone unafraid to admit they are out of their comfort zone-just as I was in that very first study tour-to show that I am still in the process of asking questions, making mistakes, and learning new things. Mary Beattie has described this kind of teaching as "a relational endeavor," wherein the role of the teacher shifts from that of an "all knowing," "all powerful," "superior" being to that of "guide and co-learner" (2000, p. 10). Instead, teachers model active learning for their students and demonstrate that education is a life-long practice.

In response to the growing popularity of study abroad programs in universities in recent years, there has been some discussion of the importance of preparing academic staff properly for the task of running them. A recent article in the Chronicle of Higher Education reports that staff often lack administrative knowledge and must juggle other academic responsibilities. Consequently, "colleges have discovered that relying on faculty members to organize study-abroad trips does not always go as smoothly as hoped" (Fischer, 2010). That may be true, but as Indiana University-Purdue University at Indianapolis professor Maggie Stimming argued in a response, staff can also benefit from the "opportunity to travel and gain an international perspective, experience international/cultural education/immersion, and [. . . language training" (2010). In addition, study abroad subjects give teachers-especially junior staff-the opportunity to identify an appropriate teaching persona. In my case, I learned to approach the classroom minus the anxiety caused by 
playing the "expert," confident from the insight that students benefit from learning alongside their teachers rather than just from them.

\section{Jennifer Spinks: Object-Based Learning}

As a new PhD candidate working on German print and visual culture in the 16th century at the University of Melbourne, in 2002, I decided to enroll in the overseas course "Renaissance Nuremberg and Central Europe." It was a double-credit intensive course for undergraduate students, but non-credit participants were also allowed to enroll. It ran for over three weeks, with twenty students based mostly in the small German city of Nuremberg. The study tour had already been run several times by my PhD supervisor Professor Charles Zika. ${ }^{2}$

Within several years, I taught on the study tour as a tutor (2006), and eventually joined it as a co-lecturer (2008). My experience of this subject over three iterations therefore shifted from the role of a student participant to that of a teacher, and this transition provided me with unique insights into learning and teaching onsite. Being involved in overseas teaching as an early career academic dramatically and positively affected my professional development, and did so in a timely way. It was especially pivotal for deepening my understanding of material culture and collections-based teaching and research, and I will return to this below.

One striking memory is that nearly every meal was eaten as a group, with conversations about German culture and history seguing into bigger discussions about history and about life. While teaching overseas was exhausting (allowing no time for personal research or indeed any down time at all), it was immensely rewarding. Feedback from students made it clear how different this was from any ordinary form of teaching and what an unforgettable aspect of their studies it represented (Atherton \& Moore, 2016, pp. 81-100). As a teacher, it increased my sense of the value of sustained contact with students in small groups - a pedagogical model that is in danger as universities increasingly value cost-effective large subjects with a healthy financial bottom line (Cartney \& Rouse, 2006, pp. 79-91). I would not be honest if I did not admit that I sometimes had qualms about the level of financial privilege that underpins the opportunity to study overseas. While costs were kept as low as possible, and many students worked and saved money in order to take the opportunity, there is no doubt that this is a form of teaching that feels inaccessible to some students. ${ }^{3}$ This gave me healthy respect for fundraising, private scholarships, and other attempts to give privileged opportunities like this to as many students as possible. It also made me more determined to "bring home" some of the intellectually exciting aspects of overseas teaching-notably contact with cultural collections — and build them into my day-to-day teaching.

\footnotetext{
${ }^{2}$ He developed the course with art historian Professor Dagmar Eichberger. See: Zika. C. (2011). Teaching and learning history "on the spot" in Europe: A reflection. In S. Broomhall, T. Pitman, \& J. McEwen (Eds.), A classroom like no other: Learning and teaching in Australian educational tourism (pp. 49-53). Perth, Australia: Australian Teaching and Learning Council. Charles noted that he was "emboldened" as a teacher by the activity (p. 51). ${ }^{3}$ This is an issue, alongside barriers like language training, that has been examined in relation to semester-length study abroad models internationally. See, for example: Salisbury et al. (2009). Going global: Understanding the choice process of the intent to study abroad. Research in Higher Education 50(2), 119-143. For an overview from an Australian perspective that touches on financial barriers, see: Gribble, C., \& Tran, L. (2016). International trends in learning abroad. Melbourne, Australia: Universities Australia/International Education Association of Australia.
} 
"Renaissance Nuremberg and Central Europe" was a course that took the adjective "intensive" seriously. The group often set out early in the morning for site visits around Nuremberg and further afield to other cities including Wurzburg, Bamberg, and Munich, and the day's tasks did not stop until late in the evening. We held lectures in a Nuremberg space leased for teaching, held tutorials with two-volume printed readers (lugged as heavy physical objects from Australia) in all sorts of locations, got the students enrolled as readers in a local library, and had them prepare an assignment due for presentation during the trip as well as begin work on an article due soon after its conclusion.

Why place Nuremberg at the heart of an overseas intensive course on late medieval and early modern Europe? The city was a pivotal center of trade, imperial and patrician politics, art, print, and humanist culture, and religious activity in this era. Its status was due to several factors: a strong patrician form of government and, despite the lack of a university, the very active intellectual and commercial involvement of artists and intellectuals in the city's burgeoning print culture. Nuremberg was also the home, at this time, to the artist Albrecht Dürer, who remains a household name, with his surviving home a draw for many tourists to the city. The religious history of Nuremberg is particularly rich and demands immersion in the spatial environment. Nuremberg saw pogroms against its Jewish community in the late medieval period, with land appropriated for patrician housing and a new church. It also experienced, adopted, and sometimes resisted the German Reformation of the 16th century in particularly interesting ways, while saving its many religious artworks from the 16th-century iconoclasm that often destroyed objects in nearby cities.

Nuremberg is also indelibly marked, of course, by its role in World War Two, both as a site of the visualization and practice of Nazi ideology in the notorious rally grounds, and as the location of the post-war Nuremberg trials. Nuremberg's late gothic and Renaissance buildings, including a castle and several famous churches, were devastated by bombings in early 1945. The city's architectural fabric was later meticulously reconstructed (its medieval and early modern artworks were, controversially, hidden for part of the war and therefore survived). The city now exists simultaneously as an original and a duplicate. This offered intriguing jumping-off points for historical reflection and triggered debates among students about the interaction between different historical periods and the layering of urban history, a complex thing to untangle when an urban space is the resource (Macdonald, 2009, pp. 117-134). The students embraced all its layers as "their" city, even though most had been originally attracted more by a summer history course in Europe than by Nuremberg specifically. But within days they developed an intimacy with the small city, its winding steep streets, surviving (and sometimes controversial) wall stone carvings, market, leafy beer gardens, and cool church interiors during the sticky heat of a German summer.

Studying the late medieval and early modern period did not shelter students (or staff) from the ethical challenges of studying history. Should artworks have been saved during World War Two, when people were not? How do we write spatially and materially rich histories of persecuted groups such as Nuremberg's medieval Jews when their presence has been all but eradicated? Can and should we empathize as historians with figures such as Nuremberg's "master executioner" Franz Schmidt? This oddly sympathetic figure carefully added up the executions and punishments he carried out, and lived - as students could experience firsthand - in a spatially marginalized, shameful part of the city that reflected his dishonorable status. Thinking about these issues continues to resonate in my teaching and research, most notably in a collaborative course on the "History of Violence" (co- 
taught with a co-author of this article) that comparatively examines the modern and early modern periods.

As an early career teacher and a specialist in early modern European history, my time in Nuremberg also brought home to me an important, pragmatic lesson about history in Anglophone universities. One of the challenges of teaching European history to undergraduates in Englishspeaking countries is the need to work on topics with rich historiographies and readily available translated materials in English (Corley, 2013). Nuremberg offered that, boasting an unusually rich range of English-language primary and secondary resources. Students were sometimes deterred from further pursuing a close interest in a particular topic by a lack of translated materials: this passed on a tough but useful message about the centrality of language study to history training at advanced levels, and required tactful and energetic steering of students towards areas for which rich resources were available. (It also encouraged some students to continue with language study in the future.) Given the richness of the visual culture and built environment surrounding us, it was not difficult to help students identify interesting topics and sources. But the compressed time of the teaching period in Nuremberg forcefully brought home to me that doing history in a field that is not always immediately accessible presents challenges. It means thinking hard about ways to develop pathways into teaching and research that are open to new learners and non-specialists. Material and visual culture (alongside translated texts) can provide an ideal and intellectually exciting pathway, and during our time in Germany students had access to exceptional visual and material collections in museums, galleries, and archives, often with generous support from the specialist staff who worked there. As academics grapple with questions of impact and relevance, and many universities cut teaching in areas requiring specialist languages, scholars need to develop strategies for survival and for relevance. Teaching overseas gave me a new perspective on these challenges.

I will close with the first benefit that I outlined: the opportunity to teach in heritage environments and cultural collections set me on a path with my teaching and research that has allowed me to develop substantial and enriching links with colleagues working outside universities. The course was ideally placed to foster my own interest in teaching using non-textual sources: paintings, sculptures, architecture, spatial relationships, and everyday and elite forms of material culture (Harvey, 2009). Fusing this inspiration with an earlier career working in art galleries, I was cocurator of several exhibition projects on early modern history that not only afforded students opportunities to become involved in cultural collections, but also allowed me to reach out to wider audiences in the community. ${ }^{4}$ This attention to material culture and collections has also affected my approach to assessment. I have since developed a course based on material culture (at a former university), in which one assignment required students to write a museum-style interpretive text about the daily life of an individual with an accompanying selection of objects drawn from online databases. Students described the utensils, clothes, furniture, and sentimental objects that might have been owned by characters ranging from elites to maidservants. This was an eye-opening exercise for students who thought more deeply about why some objects from the past survive, and in particular about how we access the past lives and experiences of non-elites. More recently, I created an

\footnotetext{
${ }^{4}$ See, for example, the student-focused website Melbourne Prints (https://melbourneprints.wordpress.com), which I developed with Catherine Kovesi, Tim Ould, Robyn Sloggett, and Charles Zika in the lead-up to the 2012 National Gallery of Victoria exhibition The Four Horsemen: Apocalypse, Death and Disaster (which I co-curated with Cathy Leahy, Petra Keyser, and Charles Zika).
} 
assignment requiring students to use objects to convey an important aspect of the history of globalization and to virtually "curate" an exhibition on that theme. In a satisfying development, curatorial staff at the university then worked with one student to develop his project on the global histories of tea and coffee into a display utilizing material from the university's special collections. My aim has been for students to see cultural collections as resources for studying during their degrees and also as professional settings that allow them to develop a richer sense of possible history-based careers. ${ }^{5}$

Working with students alongside collections and collection specialists in my home cities of Melbourne and Manchester over the past decade has allowed me to rework some of the excitement and tangibility of "being there" that is fostered by an overseas intensive. The built environment and above all the intensity of teaching and learning relationships forged through days and weeks together are harder to replicate. Overseas teaching remains an unparalleled way for students and staff to stretch themselves personally and intellectually-and to find new ways to engage with important developments in history as a profession.

\section{Cassandra Atherton: Bringing a Spirit of Adventure to the Classroom}

When I moved from Melbourne University to take a position at Deakin University, I wanted to give my new students the benefit of the overseas study tour experience that Melbourne students found so enriching. I immediately encountered practical difficulties translating what worked so well at Melbourne-one of Australia's wealthiest, most prestigious universities- to my new setting. Deakin is a middle-ranked university, and the campus I taught at was located in the small, economically depressed city of Geelong. Funding was not as generous as I had known at Melbourne, and the students came from generally less affluent backgrounds. In order to make the study tour financially viable, I had to help students access student loans offered by the Australian government, and take advantage of Deakin's sister relationship with Jonkoping University in Sweden to keep costs down.

Very few of my Deakin students were well-traveled, and some did not even possess passports. They saw a trip to faraway Sweden as a once in a lifetime opportunity. Sweden's exotic nature was heightened by the fact that, as creative writing students, they did not have the grounding in Swedish history and culture typical of a history student. While this might not have adhered to the usual "bookended" approach to study tours, where the tour is preceded and followed by reading and classes, it was perfect for a creative writing tour, whose aim is to place students in a situation in which they are outsiders. Although the writer's axiom is to "write what you know," being too close to your subject means that you lose perspective. ${ }^{6}$ For students who had rarely ventured far from the small, provincial city of Geelong where they had grown up, the need for distance was even more

\footnotetext{
${ }^{5}$ Key teaching strategies are outlined in Burnham, R., \& Kai-Kee, E. (2005). The art of teaching in the museum. Journal of Aesthetic Education 39(1), 65-76. Innovations in teaching with material culture also include bringing collections to purpose-built teaching environments. This is a key pedagogical technique in the Arts West Building at the University of Melbourne (opened 2016), which has a purpose-built Object-Based Learning Laboratory.

${ }^{6}$ The axiom "write what you know" is referred to in Mokhtari, T. (1988). The Bloomsbury introduction to creative writing. London, UK: Bloomsbury (p. 35). The danger of being too close to a subject is explained in Neale, D. (2006). Using memory, remembering lives. In L. Anderson (Ed.), Creative writing: A workbook with readings. Milton Park, UK: Routledge (p. 321).
} 
pressing. The study tour gave them this distance. As Angela Passarelli and David Kolb explained, "By living, studying and working in an unfamiliar culture, students are challenged to make sense of the novelty and ambiguity with which they are regularly confronted" (Passarelli \& Kolb, 2012, p. 137). Essentially, by immersing the students in a strange culture, we had given them the opportunity to become "cultural anthropologists" and write in ways that they never thought possible (Le Rossignol \& Atherton, 2016).

The danger was that having our students experience Sweden together might dampen the strangeness. They roomed and dined together, and our discussion classes-normally such a productive activity - meant that they interpreted Sweden collectively. To maintain the students' detachment, I made sure that they occasionally immersed themselves in cultural activities as individuals. The event that made the deepest impression was the Midsummer celebration. Dating back to pre-Christian solstice festivals, Midsummer today is essentially a celebration of Swedish culture, with people gathering to dance around the maypole and eat traditional food such as herring and new potatoes. We sensed the holiday atmosphere as we walked from the university to Jonkoping Stadspark (Jonkoping City Park). Then I had the students disperse into the crowd. The bravest ones tried sma grodorna (a dance in which people try to imitate jumping frogs), some joined the circle around the maypole, and even the less adventurous ones listened to the traditional Swedish music and observed things such as young girls wearing floral wreaths in their hair, which the students learnt was a way of harnessing nature's magic and ensuring good health throughout the year to come.

The Midsummer celebration served as an "intercultural red flag." The familiarity of Swedish stores that have spread to Australia, such as H\&M and Ikea, the generically modern rooms in our Jonkoping hotel, and university classrooms at our host university that were very similar to the ones at home made Sweden seem all too comfortable. The absence of a language barrier also helped make Sweden seem familiar. None of our students spoke Swedish, but though we thought this would set us apart from the natives, we discovered that Swedes almost universally spoke fluent English. All that changed at the Midsummer celebration. Announcements, speeches, and conversations swirled around us in Swedish. With its sma grodorna dancing, traditional costumes, and picnic food such as gubbrora (egg-anchovy salad), the celebration was different enough to jolt the students out of their cultural comfort zone and give them the outsider's perspective needed to generate insightful writing. Importantly, they experienced the strangeness individually, and I made sure that they each wrote about the Midsummer celebration in their journals before they had the chance to discuss it as a group.

The results were mixed. Feeling puzzled and out of place is never easy, but some of the students responded with thoughtful journal entries in which they tried to understand quirks that even the Swedes themselves might not recognize. These journals, in which the students grew as writers, made the study tour seem worthwhile. The exercise exposed insecurities in others. Compared to the comfortable certainties they wrote about at home, writing as the outsider was hard. They doubted the worth of their observations and shrank from the challenge. Some wrote in a

7 "Red flags" is a term developed by Professor Elijah Lovejoy of UC Santa Barbara. See: Seelye, H. (Ed.) (1996). Experiential activities for intercultural learning. Boston, MA: Intercultural Press. See especially Section V: Analyzing Cross-Cultural Incidents. 
frivolous, dismissive way, some wrote perfunctory descriptions of what they saw, and some, searching for a crutch, tried to write in the style of the Scandinavian noir they had read in preparation for the trip.

I resolved to confront the insecurities that surfaced in Sweden in my classes back in Geelong. Of course, not every student was going to write bravely and well, and very few of them would get their dream writing job. Nevertheless, I wanted to at least show them the possibilities. As previously noted, very few Deakin students had the means to travel overseas, but I encouraged them to do what they could to put themselves in a strange setting. They were young, so why not spend some time at a senior citizens club? One specific example of a student embracing this approach was an atheist non-churchgoer who attended a church service and then mixed with parishioners afterwards at an afternoon tea. Her notes were the basis of an insightful short story full of rich description. I also had an historian give a lecture to the students about the possibilities of immersing themselves in archives and transporting themselves to the past. None of these things were as exotic as being at a Midsummer celebration in Sweden, but students could still act as cultural anthropologists and write with an outsider's detachment. Pedagogically, I was doing what Adam Scarfe has described as "bringing an adventurous spirit into the classroom." According to Scarfe, this spirit can have a positive effect on students who are feeling disinterested and defeated (2009, p. 5).

However, the study tour did not just change what I taught in the classroom, it also changed how I taught. I had always tried to make my lectures stimulating and exciting. In effect, I tried to inject a note of theater into them. Such theater allegories for the classroom, and discussions of the teacher as actor are not new. Seymour Bernard Sarason has argued, "Teachers are actors. We perform" (1999, p. xi). Similarly, Nike Imoru has written that "the educative performance [is] a performance of the self." He identifies "a dynamic at play [in the classroom], the dynamic of the self, myself as lecturer (as actor), in tandem with the material and the students (as spectators)" (2000, p. 130). However, on an overseas study tour, the students are expected to be more than spectators; they are participants in the performance. Accordingly, the teacher's performance turns on his/her skill in improvisation, and its success is determined by the way in which the students can be included as protagonists in this play. The challenge is that there is no script and no rehearsal in this live performance and that it spans three weeks (Atherton, 2013, p. 153).

Seeing the positive way in which students responded to the unscripted, less structured interaction of the study tour, I adapted my lectures and tutorials accordingly. My lectures were still meticulously researched, but my presentation became more conversational. Tutorials became occasions in which the students were, as on the study tour, expected to be more than spectators. In what amounted to versions of the study tour de-brief sessions, they were given the opportunity to talk about their "out of place" investigations of the senior citizens meeting at the local church. These often hilarious reports had a flow-on effect when the students came to present the writing that had flowed out of their investigations. Many students find the creative writing workshop, in which the class critiques their work, difficult. However, after doing the hard work of amateur cultural anthropologists, and then having that experience validated in a light-hearted classroom discussion, they were more relaxed about sharing their writing with the class. 
The study tour was an adventure, and after seeing the potential for students to react positively, I tried to inject the same spirit of adventure in the classroom. I encouraged the students to write bravely about subjects that were not familiar to them, and after putting their work in front of their peers in the classroom, some felt brave enough to submit to publishers. A few succeeded in having work published, but the fact that others had simply tried something that they wouldn't have dared do before taking my class made me glad that I heeded the lessons of the study tour.

\section{Paul Hetherington: Teaching Through the Visual}

The three study tours I have conducted through the University of Canberra with (primarily) creative writing students have grown out of my enthusiasm for combining travel and teaching in a way that also relates to deeply-held pedagogical convictions-I have taken students to Rome and Florence; then to Osaka, Kyoto, and Tokyo; and recently to Barcelona and Madrid. I have always believed that the best kind of teaching involves a combination of theory and practice and, while that is an old idea, in contemporary universities it can be difficult to find ways of enabling students of creative writing to fully understand that creative practice is not simply about writing their next poem or piece of fiction. Except where the most gifted students are concerned, such works-usually produced with little change to students' way of living or knowledge of the world - tend to be fairly pedestrian, not only because students are usually inexperienced writers, but because they are often inexperienced at life.

Perhaps this is one of the roots of David Morley's advice about what creative writers should aim for in undertaking their practice. Among 39 eclectic points, he advises writers to "[d]efamiliarise the world, to make us see things afresh, as if for the first time" (2007, p. 90). As a teacher I have tried various methods to enable students to practice such "defamiliarization" - an example is a pedagogical experiment that I conducted with a colleague a few years ago where an "observation and figurative language exercise" we constructed for undergraduate students enabled them to write about their city with fresh creative insights:

The observation and figurative language exercise demonstrate[d] that by carefully defining and delimiting the task of writing poetry, by focusing it on observations about a city that students lived in and knew ... students with relatively little or no prior experience of writing poetry were able to produce works with real promise. The Imagist techniques . . . and the associated reading, enabled students to . . . make clear connections between observed, quotidian detail and their more figurative poetic gestures. (Strange \& Hetherington, 2014, p. 16)

However, such pedagogical methods have their limits because they are almost always conducted on the campus or within a city that students inhabit and know well. Defamiliarisation of such environments is possible, and can be extremely valuable to creative writers, but it is not the same as taking students to genuinely unfamiliar and unsettling environments. Our pedagogical exercise in Canberra offered students techniques for re-seeing and re-conceptualizing their city, but it could not bring them to new places where even the roads and footpaths were different from those they knew.

Cassandra Atherton and Karen Le Rossignol have written about "unsettling creativity" and the benefits of taking students away from their familiar environment, stating that: 
[p]roviding a productive discomfort, by challenging students to move outside their comfort zones on short term Study Tours ... is a strong preparation of students for their graduate role as global citizens. (2016, p. 303)

In order to tease out this issue of the value of the unfamiliar, I will concentrate on the first study tour I conducted-Rome in 2015. I undertook this tour because I was awarded an Australia Council for the Arts residency to spend six months at the B.R. Whiting studio, an eighth-floor apartment in the Trastevere area of Rome. Trastevere is a fairly expansive district, and includes a medieval quarter on the Tiber River's west bank that is full of old and picturesque buildings, many restaurants, churches (notably the Basilica di Santa Maria and Santa Cecilia), and the Galleria Nazionale d'Arte Antica di Palazzo Corsini (the National Gallery of Antique Art in the Corsini Palace). Trastevere is also not far from Testaccio's superb fresh food markets.

I mention these few features of Trastevere-and there are many others-simply to indicate the culturally rich and deeply layered environment to which the students were traveling. The cultural features of Rome more generally are, of course, far too many to enumerate and include some of the wonders of the world. I had committed to writing a series of ekphrastic prose poems in Rome provisionally entitled "Roman Paintings," which involved visiting many of Rome's galleries and museums in order to garner ideas for my writing, and I thought of taking students with me for a couple of weeks-including to Florence, which became the second leg of the two-week study tour-to write about their experiences there and share my enthusiasm for the visual arts.

In practice, of course, I had to plan a structured itinerary for the tour and try to make it an extended pedagogical experience suitable for undergraduate students who may have had little knowledge of the visual arts. Nevertheless, I wanted to preserve my initial impulse, so I called the tour "Poetry and the Visual Image in Italy," indicating to prospective students what they would be in for. On the advice of the university's Study Abroad and Exchange team, I made use of an external provider - the CiSAustralia organization - to help plan the tour's itinerary and to provide staff on the ground in Italy to support the students.

In setting an itinerary for Rome and Florence, the challenge was not so much determining what to include in the tour as what to leave out. In Rome, we scheduled visits to places such as the Vatican Gardens, followed by entry to the Vatican Museums; the Sistine Chapel and St. Peter's Basilica; the Galleria Borghese; the Non-Catholic Cemetery where Keats and Shelley are buried; the Keats-Shelley House Museum; the Maxxi Museum; and the Santa Maria della Concezione dei Cappuccini, including its famous crypt. In Florence, we scheduled visits to the Galleria degli Uffizi, the Giardini Boboli, the Palazzo Pitti, Michelangelo's house, Santa Croce, and Santa Maria del Fiore (the Duomo). We also ensured that students would receive a varied combination of walking and "neighborhood" tours, along with unscheduled time (and the opportunity to go to the beach), including eating and drinking in a variety of places that they may not otherwise visit. We also took them to markets in both cities.

Stacie Travers has written that "[i]mmersion and participatory involvement" provide "the opportunities for experiential learning, but what turned these opportunities . . . into actual learning was the ability to attach meaning and/or purpose to their experiences in context" (2013, p. 204). Such a sentiment is close to my heart and perhaps the best way of achieving this end, apart from 
drafting a strong itinerary, is to ensure that student assignments are closely connected to their experiences while traveling.

I devised a group of assignments that required students to write in a poetry and visual image creative journal every day. While the journal was not an assessable item, I asked for it to be handed in at the end of the trip to ensure that everyone understood that its completion was mandatory. The journal was primarily for students to record their "thinking about the unit," discuss readings, draft their creative assignments, record "associated research issues and sources" and details of artworks they had seen, and to make personal notes and record impressions. I asked students in particular to "trace some of [their] patterns of excitement (or boredom) when viewing art" and to "make a note about [their] responses to particular artworks." 8 The assessable items were ten "perfect sentences," written between days two and 11 of the study tour; an ekphrastic creative work (in either poetry, prose poetry, or prose) relating to one or two artworks; and two additional creative works incorporating visual imagery from at least three artworks identified during the program.

In practice, this well-planned study tour was reasonably successful despite some real difficulties. The main and overriding problem was the time of the year. In planning the tour we wanted to enable students to participate during the university's Winter Intensive Term-a short, mid-year semester-in order to have time to travel back home to begin semester two. This made sense at the time but the hot weather in Rome in August was far worse than we had anticipated, to the extent that even our local CiS staff struggled with the heat. It was well over 100 degrees in the shade on some days and the heat wave continued throughout the tour, although our week in Florence was marginally better than our week in Rome. Fortunately, we had booked air-conditioned transport for a number of the days of the tour, and Rome has many nasoni, or free drinking fountains, which proved essential to our wellbeing when we were walking.

It was also fortunate that the group was relatively tight-knit and consisted of only 12 students, almost all of who showed a strong sense of responsibility. One student became ill when we were at the Vatican Museums and was attended to by paramedics. She had high blood pressure and tachycardia and was placed in a wheelchair. When she recovered, however, she embraced the tour's experiences enthusiastically and became one of its most engaged members. A second student decided to go home, although it was not entirely clear whether this was due to the heat or other issues.

Because of the weather we reduced scheduled visits and modified other aspects of the tour, allowing students additional free time. We also visited Rome's Non-Catholic Cemetery a second time because it was a cool and appealing environment, and students had said they would like to have a few additional hours there to write. We consumed considerable amounts of gelato. Because the Italian accommodations were not always air-conditioned, many students did not sleep well, but as the tour went on they became more and more entranced by what they saw. It turned out that many

\footnotetext{
${ }^{8}$ The quotations in this paragraph are from an unpublished document entitled "Special Studies in Communication 1 (7555|5)," Customized Faculty-led Program, University of Canberra, Poetry and the Visual Image in Italy, August 6$18,2015,7$.
} 
of them enjoyed their immersion in the cityscapes and buildings of Rome and Florence as much as, or more, than their visits to galleries, although some loved that aspect of the tour.

From a pedagogical point of view, the tour was a success. Student feedback was generally very positive despite the difficulties and the group meshed remarkably well, partly in supporting one another. With such a small group there were frequent opportunities to talk informally while walking from one destination to another, not only about writing and assignments, but about general matters to do with art and life. From time to time I also discussed assignments with small groups of students in their apartments, which proved to be a constructive way of teaching. Such informal exchanges enriched the learning experience for everyone. I also learnt a great deal from seeing works of art with a fresh eye while trying to explain their significance and cultural contexts to a class.

There were a number of lessons I brought back to the University of Canberra. The most important of these included the realization that even creative writing students who have no great interest in or prior knowledge of the visual arts will respond positively to encountering and considering complex artworks, and incorporating imagery from such works into their creative writing. As a result, I have increasingly asked students to respond to visual imagery in their writing assignments in order to emphasize that, because we live in a visually rich culture, in many cases "reading" our culture involves responding to and comprehending visual imagery as much as it involves responding to language. A simple but effective example is an assignment a colleague and I recently set that required students to write short prose fragments in response to photographs they had taken of a city.

I was also persuaded of the importance of experiential learning that genuinely "unsettled" students and asked them to bring their whole being to their learning experiences. Since the study tour in Rome, in addition to trying to help undergraduate students work productively in classroom situations, I have also devised more assignments that involve "real-world" engagement. For example, I now regularly ask students to place themselves in unfamiliar circumstances, preferably outside of Canberra, and produce creative works in response to those experiences. This may be something as simple as asking them to walk away from their family or friend group when traveling, and taking time to observe and record what they see or otherwise notice.

For all of us, the study tour to Rome and Florence was unforgettable and though this was not always for the most desirable of reasons, the circumstances of the tour brought a great deal out of students - even some who started the tour shyly and quickly became assertive and engaged. When I teach undergraduates at the University of Canberra, I always try to remember that the students who went to Rome produced some very good writing and made it through difficulties in order to understand and reflect on art that forcibly struck them as they traveled. The classroom is almost always a wonderful place, and the more it can be opened up to the wider world-whether through taking it to other countries and cities, or by other means - the better and more expansive it is.

\section{Conclusion}

The five case studies in this article show how taking overseas study tours had positive impacts on the classroom-based teaching of the professors involved. Seeing what worked in the field led each of the professors to change their approach in the classroom, and in each case the result was 
improved student outcomes. At a deeper level, seeing students respond so positively to the challenges of an overseas study tour, and then successfully replicating these results in the classroom, rekindled the professors' belief in the future of the liberal arts in universities.

There were two broad ways in which the lessons learned from running study tours were applied to the classroom. Seeing how students responded to and learned from the material objects they encountered in museums, art galleries, and historic sites led to attempts to replicate that experience in the classroom. Paul Hetherington did this by sending his creative writing students to nearby art galleries, but Jennifer Spinks found ways for her history students to engage with material culture in the classroom itself. As she explained, by using images and descriptions of utensils, clothes, furniture, and "sentimental objects," she gave her students a feel for everyday life in the past. The second way that the study tour experience was applied to the classroom was through changed teaching philosophies. Glenn Moore and Cassandra Atherton both tried to inject the sense of excitement they had seen in the field by challenging their students to grapple with new and sometimes complex ideas in the classroom. As a junior staff member, Katherine Ellinghaus used her overseas study tour experience to develop a teaching persona that worked for her. In particular, the one-on-one interactions that are such an inherent part of an overseas study tour gave her the courage to abandon the top-down "expert teacher" model with which she felt uncomfortable, and be confident that students can learn with their teachers rather than just from them.

It was tempting to see a clear division between the professors who developed new teaching strategies based on their study tour experiences, and those who saw the possibilities of using more material culture in the classroom. But as we wrote the article, we found a large degree of overlap. Indeed, the two approaches seemed to feed into one another. Glenn Moore found that part of challenging history students involved asking them to look beyond text books, instead using primary material such as floor plans and lists of the belongings of tenement dwellers to get insight into everyday life for immigrants in the Gilded Age. Conversely, Jennifer Spinks found that to facilitate the use of material culture in the classroom she had to develop new assessment models. For instance, rather than giving students an exam or assigning them an essay, she asked them to curate a museum exhibition using the objects they were working with.

Using methods that worked on overseas study tours to improve classroom experiences was important in two ways. While a lot of research has explored the short- and long-term value of overseas study tours for students, the five examples in this article show how learning to run a successful study tour can also have valuable flow-on effects for the university teacher's own professional development and teaching strategies. Being able to successfully apply methods developed in running their study tours to the classroom also boosted teacher morale. Indeed, seeing the way in which students became excited about being challenged with complex ideas and being asked to work directly with material culture rekindled the professors' belief in the future of the liberal arts or humanities in universities. Administrators who worry about students turning away from the liberal arts would do well to take note of these results. 


\section{References}

Atherton, C., \& Le Rossignol, K. (2016). Unsettling creativity: Intercultural spaces, study abroad and internationalization beyond the curriculum. In J. Freitas De Luna (Ed.), Internationalization of the curriculum: Education, interculturality and global citizenship. Brazil: Brazilica Publishing House.

Atherton, C. (2013). All the world's a stage: The production of an overseas intensive. In G. Moore (Ed.), Searching for the American dream: How a sense of place shapes the study of history. Newcastle upon Tyne, England: Cambridge Scholar's Publishing.

Atherton, C,. \& Moore, G. (2016, December). Student perspectives on the value of experiential learning in history. Australasian Journal of American Studies, 35(2).

Bader, M. (2013). Place-based education at the tenement museum. In G. Moore (Ed.), Searching for the American dream: How a sense of place shapes the study of history. Newcastle, UK: Cambridge Scholars Publishing

Beattie, M. (2000). Narratives of professional learning: Becoming a teacher and learning to teach. Journal of Educational Enquiry, 1(2).

Boucher, L., \& Arrow, M. (2016). 'Studying modern history gives me the chance to say what I think': Learning and teaching history in the age of student-centred learning. History Australia, 13(4).

Burnham, R., \& Kai-Kee, E. (2005). The art of teaching in the museum. Journal of Aesthetic Education, $39(1)$.

Carlson, P., \& Fleisher, M. (2002). Shifting realities in higher education: Today's business model threatens our academic excellence. International Journal of Public Administration, 25(9-10).

Cartney, P., \& Rouse, A. (2006). The emotional impact of learning in small groups: Highlighting the impact on student progression and retention. Teaching in Higher Education, 11(1).

Coker, J., \& Porter, D. (2015, January/February). Maximizing experiential learning for student success. Change.

Corley, C. (2013). From mentoring to collaborating: Fostering undergraduate research in history. The History Teacher, 46(3).

Cruickshank, D. (1985, March/April). Applying research on teacher clarity. The Journal of Teacher Education.

Cullen, J. (2003). The American dream: A short history of the idea that shaped a nation. New York, NY: Oxford University Press.

Dewey, J. (1938). Experience and education. New York, NY: The Free Press.

Ellinghaus, K. (2013). Getting there. In G. Moore (Ed.), Searching for the American dream: How a sense of place shapes the study of history. Newcastle upon Tyne, UK: Cambridge Scholars Publishing.

Eyler, J. (2009, Fall). The power of experiential education. Liberal Education. 95(4).

Fischer, K. (2010, February 7). More colleges coach professors to lead study-abroad trips. Chronicle of Higher Education.

Gair, N. (1997). Outdoor education: Theory and practice. London, UK: Cassell.

Grasha, A. (1994). A matter of style: The teacher as expert, formal authority, personal model, facilitator, and delegator. College Teaching, 42(4).

Greenway, R. (2007). Dynamic debriefing. In M. Silberman (Ed.), The handbook of experiential learning. San Francisco, CA: Pfeiffer.

Gribble, C., \& Tran, L. (2016). International trends in learning abroad. Melbourne, Australia: Universities Australia/International Education Association of Australia.

Harvey, K. (2009). History and material culture: A student's guide to approaching alternative sources. London, UK: Routledge.

Hativa, N., Barak, R., \& Simhi, E. (2001, November/December). Exemplary university teachers. The Journal of Higher Education, 72(6).

Hochschild, J. (1995). Facing up to the American dream: Race, class, and the soul of the nation. Princeton, NJ: Princeton University Press. 
Katherine Ellinghaus et al.

Imoru, N. (2000). Performance and pedagogy: The signifying monkey and the educative I/eye. In A. Donnell \& P. Polkey (Eds.), Representing Lives: Women and Auto/biography. London, UK: Macmillan Press.

Kiely, E. (2005, Fall). A transformative learning model for service-learning: A longitudinal case study. Michigan Journal of Community Service Learning.

Kolb, D. (1984). Experiential learning: Experience as the source of learning and development. Englewood Cliffs, N.J.: Prentice Hall.

Kutchel, D. (2015, September 6). Uni intensives: The zoom, zoom, zoom of study. The Age.

Macdonald, S. (2009). Reassembling Nuremberg, reassembling heritage. Journal of Cultural Economy, 2.

MacNeil, L., Driscoll, A., \& Hunt, A. N. (2015, August). What's in a name: Exposing gender bias in student ratings of teaching. Innovative Higher Education, 40(4).

McPherson, J. (2000). Gettysburg. In W. Leuchtenburg (Ed.), American places: Encounters with history. Oxford, UK: Oxford University Press.

Mokhtari, T. (1988). The Bloomsbury introduction to creative writing. London: Bloomsbury.

Morley, D. The Cambridge introduction to creative writing. Cambridge, UK: Cambridge University Press, 2007.

Neale, D. (2006). Using memory, remembering lives. In L. Anderson (Ed.), Creative writing: A workbook with readings. Milton Park, UK: Routledge.

Parini, J. (2005). Art of teaching. New York, NY: Oxford University Press.

Passarelli, A., \& Kolb, D. (2012). Using experiential learning theory to promote student learning and development in programs of education abroad. In M. V. Berg, R. M. Paige, \& K. H. Lou (Eds.), Student learning abroad: What our students are learning, what they're not, and what we can do about it. Sterling, VA: Stylus Publishing.

Pritchard, S. (2015, June 23). Should female faculty get bonus points to correct for gender bias in student evaluations. The Conversation. Retrieved from https://theconversation.com/should-female-facultyget-bonus-points-to-correct-for-gender-bias-in-student-evaluations-43166

Reda, M. (2009). Between speaking and silence. New York, NY: State University of New York Press.

Ryenaud, D., \& Northcote, M. (2011). Have passport, will learn: History study tours and student learning and development. Research and Development in Higher Education: Higher Education on the Edge, 34.

Salisbury, M. H., Umbach, P. D., Paulsen, M. B., \& Pascarella, E. T. (2009). Going global: Understanding the choice process of the intent to study abroad. Research in Higher Education, 50(2).

Sarason, S. (1999). Teaching as performance art. New York, NY: Teachers College Press.

Scarfe, A. (Ed.). (2009). The Adventure of education: Process philosophers on learning, teaching and research. New York, NY: Brill Rodophi..

Seelye, H. (Ed.). (1996). Experiential activities for intercultural learning. Boston, MA: Intercultural Press.

Silberman, M. (2010). Unforgettable experiential activities: An active training resource. San Francisco, CA: Pfeiffer.

Stimming, M. (2010, March 7). Staff members should be included in study-abroad programs. Chronicle of Higher Education.

Strange, S., \& Hetherington, P. (2014). Making the city otherwise: Ways of teaching the writing of poetry. In G. Pittaway, A. Lodge, \& L. Smithies (Eds.), The Minding the gap: Writing across thresholds and fault lines papers: The refereed proceedings of the 19th conference of the Australasian Association of Writing Programs. Retrieved from http://www.aawp.dreamhosters.com/wpcontent/uploads/2015/05/Strange__Hetherington_MakingCityOtherwise.pdf

The Real Undergraduate Handbook. (2006). Farrago, V.

Travers, S. (2013). Getting the most out of studying abroad: Ways to maximize learning in short-terms study trips. In R. Tiessen \& R. Huish (Eds.), Globetrotting or global citizenship?: Perils and potential of international learning. Toronto, Canada: University of Toronto Press. 
Wurdinger, S., \& Allison, P. (2017). Faculty perceptions and uses of experiential education in higher education. Journal of e-Learning and Knowledge Society, 13(1).

Zika, C. (2011). Teaching and learning history 'on the spot' in Europe: A reflection. In S. Broomhall, T. Pitman, \& J. McEwen (Eds.), A classroom like no other: Learning and teaching in Australian educational tourism. Perth, Australia: Australian Teaching and Learning Council. 